\title{
Postoperative pulmonary complications following major elective abdominal surgery: a cohort study
}

\author{
Kamlesh Patel', Fatemeh Hadian', Aysha Ali', Graham Broadley ${ }^{1}$, Kate Evans', Claire Horder ${ }^{1}$, Marianne Johnstone ${ }^{1}$,

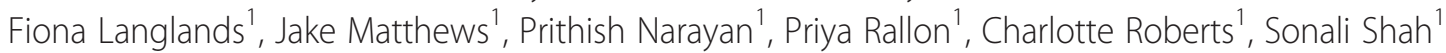 \\ and Ravinder Vohra ${ }^{1,2^{*}}$
}

\begin{abstract}
Background: Postoperative pulmonary complications (PPC) are an under-reported but major cause of perioperative morbidity and mortality. The aim of this prospective, contemporary, multicentre cohort study of unselected patients undergoing major elective abdominal surgery was to determine the incidence and effects of PPC.

Methods: Data on all major elective abdominal operations performed over a 2-week period in December 2014 were collected in six hospitals. The primary outcome measure of PPC at 7 days was used. Univariate and multivariate analyses were performed to investigate how different factors were associated with PPC and the effects of such complications.

Results: Two hundred sixty-eight major elective abdominal operations were performed, and the internal validation showed that the data set was $99 \%$ accurate. Thirty-two (11.9\%) PPC were reported at 7 days. PPC was more common in patients with a history of chronic obstructive pulmonary disease compared to those with no history (26.7 vs. $10.2 \%, p<0.001$ ). PPC was not associated with other patient factors (e.g. age, gender, body mass index or other comorbidities), type/method of operation or postoperative analgesia. The risk of PPC appeared to increase with every additional minute of operating time independent of other factors (odds ratio 1.01 (95\% confidence intervals 1. $00-1.02), p=0.007$ ). PPC significantly increase the length of hospital stay (10 vs. 3 days). Attendance to the emergency department within 30 days (27.3 vs. $10.6 \%$ ), 30-day readmission (21.7 vs. $9.9 \%$ ) and 30-day mortality (12.5 vs. $0.0 \%)$ was higher in those with PPC.
\end{abstract}

Conclusions: PPC are common and have profound effects on outcomes. Strategies need to be considered to reduce PPC.

Keywords: Pulmonary complications, Morbidity, Surgery, Postoperative

\section{Background}

An estimated 234 million patients undergo major surgery worldwide every year (Weiser et al. 2008). Approximately $16 \%$ will suffer a complication within 30 days (Kazaure et al. 2012). These include well-defined complications e.g. thromboembolic complications (NICE 2010) and surgical site infections (NICE 2013) and others

\footnotetext{
* Correspondence: ravsvohra@hotmail.com

'West Midlands Research Collaborative, Academic Department of Surgery,

School of Cancer Sciences, University of Birmingham, Birmingham B15 $2 \mathrm{TH}, \mathrm{UK}$

${ }^{2}$ Nottingham Oesophago-Gastric Unit, Nottingham University Hospitals, Nottingham, UK
}

(c) 2016 Patel et al. Open Access This article is distributed under the terms of the Creative Commons Attribution 4.0 International License (http://creativecommons.org/licenses/by/4.0/), which permits unrestricted use, distribution, and reproduction in any medium, provided you give appropriate credit to the original author(s) and the source, provide a link to the Creative Commons license, and indicate if changes were made. The Creative Commons Public Domain Dedication waiver (http://creativecommons.org/publicdomain/zero/1.0/) applies to the data made available in this article, unless otherwise stated.

which are likely to be under-reported as they do not form part of the current hospital quality measures.

One set of under-reported complications are postoperative pulmonary complications (PPC). These include a spectre of clinical conditions. PPC includes postoperative hypoxia, atelectasis, bronchospasm, pulmonary infection, pulmonary infiltrate, aspiration pneumonitis, acute respiratory distress syndrome, pleural effusions and pulmonary oedema (Arozullah et al. 2000). Depending on the severity, these can be self-limiting, require wardbased interventions e.g. antibiotics or physiotherapy, or readmission to critical care, reintubation and even death. 
Some estimates suggest that the incidence of PPC is anywhere between 5 and $40 \%$ of patients following surgeries involving the abdomen (Seiler et al. 2009; Hemmes et al. 2014; Niggebrugge et al. 1999; Treschan et al. 2012). PPC is associated with a 30-day mortality of $18 \%$ compared with $2.5 \%$ for those without PPC (Khuri et al. 2005). Even after risk adjustment, at 5 years post surgery, PPC is associated with a $66 \%$ lower survival (Khuri et al. 2005). In those who do survive, the limited available evidence suggests a detrimental effect of PPC on early and late health-related quality of life (Thompson et al. 2006). Following major elective abdominal surgery, PPC results in six to nine extra hospital days and costs the healthcare system an additional $\$ 30,000$ per patient (Dimick et al. 2004).

This data relates to studies conducted over 10 years ago. The incidence and effects of PPC may have changed with the advances in perioperative anaesthetic techniques e.g. non-invasive positive pressure ventilation, pain control adjuncts and enhanced recovery protocols (Hemmes et al. 2014; Kehlet and Wilmore 2008). The aim of this prospective multicentre cohort study of unselected patients undergoing major elective abdominal surgery was to determine the incidence and effects of PPC.

\section{Methods}

Over the past 8 years, trainee-led networks in the UK have adopted a collaborative approach to deliver prospective population-level data collections and measure patient, disease, surgical and hospital variables with short-term endpoints such as readmissions and complications (Bhangu et al. 2013). Using these networks, a prospective, multicentre cohort study across six hospitals in the UK was conducted over a 2-week period in December 2014.

\section{Inclusion and exclusion criteria}

All patients over the age of 18 years undergoing major (defined as a postoperative hospital stay of $>1$ day) elective surgery (patients admitted either the day of surgery or the night before) in the study period were included. Consecutive patients undergoing benign and cancer resections on the stomach, liver, pancreas, biliary tree, small bowel, colon, rectum, bladder, kidneys and abdominal aorta were included here. Organ transplantation and emergency operations were excluded. Cholecystectomy was also excluded as the majority are performed as a day case procedure.

\section{Primary outcome}

The primary outcome measure of PPC at 7 days was used (Additional file 1: Table S1). Demographic, intraoperative and postoperative data at day 30 were collected (Additional file 1: Table S2). The definitions for all data were derived from two recent randomised controlled trials (The PROVE Network Investigators 2014; Futier et al. 2013). Patients were investigated and diagnosed with respiratory complications as per 'routine care' at each institution.

\section{Explanatory variables}

Demographic and intraoperative data were collected here as potential explanatory variables for PPC at day 7 (Additional file 1: Table S2). Further, postoperative data at day 30 were also collected (Additional file 1: Table S2).

\section{Data validation}

To standardise data quality, a quality assurance programme has been developed for previous studies (Vohra et al. 2015). This included a detailed study protocol, a pilot phase, and a requirement for a minimum of $95 \%$ data completeness at submission. Case ascertainment and data accuracy were further validated by independent investigators at selected hospitals, who checked data correctness from $10 \%$ of patients against original medical records. These independent investigators were not involved in the original data collection.

\section{Ethical approval}

The protocol did not require research registration or consent from patients as only anonymous observational data were collected. Data collection was entirely independent of patient management, and therefore, patient management was not altered as a result of the study. This was confirmed by the online National Research Ethics Service (NRES) decision tool (http://www.hra-decisiontools.org.uk/research/) used to determine whether a study requires review from a research ethics committee in the UK National Health Service (NHS). This decision was further supported by the Research and Development Director at University Hospitals Birmingham NHS Foundation Trust, UK. The study was registered as a 'clinical audit' or 'service evaluation' at each participating hospital under the supervision of a named senior investigator (consultant or attending surgeon).

\section{Statistical analysis}

Data were collected and analysed in clinically relevant categories. Univariate and multivariate analyses, including factors with a $p<0.05$ on univariate analysis, were performed to investigate how different factors were associated with PPC and the sequelae of such complications. Missing data for predictor values were replaced using the multiple imputation method to create five imputed datasets; all predictor and outcome variables will be entered into the predictive models for imputation. 
Statistical analyses were conducted using SPSS v21 (IBM, Armonk, NY, USA). Statistical significance was set at $p<0.050$. The report of this study was prepared in accordance to the guidelines set by the Strengthening the Reporting of Observational Studies in Epidemiology (STROBE) statement for observational studies (Von Elm et al. 2007).

\section{Results}

\section{Demographics}

Over the 2-week period, a total of 268 consecutive major elective abdominal operations were performed in the six hospitals. Case ascertainment and accuracy of collected data were above 99 and $98 \%$, respectively, when compared with a $20 \%$ sample checked independently against the original medical records. Missing data were $0.8 \%$ within the entire dataset. General demographic data is shown in Table 1. Median age of the cohort was 66 years, $61.9 \%$ were male, $53.7 \%$ were ASA grade 1 or 2 and $31 \%$ were having a cancer operation. In addition, it is notable that $84.3 \%$ were administered perioperative antibiotics, $63.1 \%$ had open operations and despite all operations being classed as major operations, elective critical care use was $19.4 \%$. Endotracheal tubes were mainly used reflecting the duration and grade of the operations performed.

\section{Outcomes at day 7 and 30 (Table 2)}

A total of 32 (11.9\%) PPC were reported at 7 days, and suspected pulmonary infection was the most common $(n=24,9 \%)$. The median length of hospital stay for the cohort was 4 days, and 30-day mortality was $1.5 \%(n=4)$. Readmissions at 30 days were $17 \%$ which reflects the grade of operations performed.

\section{Effect of pre and perioperative factors (Tables 3 and 4)}

Risk factors for PPC by day 7 were a history of chronic obstructive pulmonary disease, undergoing an operation for a malignancy and a postoperative nasogastric tube. In addition, the duration of surgery associated with PPC at day 7 as was the intraoperative analgesia strategy and a change to this strategy in the first $24 \mathrm{~h}$. PPC was not associated with age, gender, body mass index, other comorbidities, smoking or type or method of operation (open vs. laparoscopic).

When these significant factors were included in a multivariate model, chronic obstructive pulmonary disease was independently associated with development of a PPC (Table 4). Further, the risk of PPC appeared to increase with every additional minute of operating time independent of other factors (odds ratio 1.01 (95\% confidence intervals 1.00-1.02), $p=0.007$ ).
Table 1 General demographics

\begin{tabular}{|c|c|}
\hline $\bar{n}$ & 268 \\
\hline Age (years, IQR) & $66(53-75)$ \\
\hline Male & $166(61.9)$ \\
\hline Body mass index (kilograms/metres $\left.{ }^{2}, \mathrm{IQR}\right)$ & $27.3(24.0-31.2)$ \\
\hline \multicolumn{2}{|l|}{$\begin{array}{l}\text { American Society of Anesthesiologists } \\
\text { physical status classification system }\end{array}$} \\
\hline 1 & $32(11.9)$ \\
\hline 2 & $112(41.8)$ \\
\hline 3 & $71(26.5)$ \\
\hline 4 & $7(2.6)$ \\
\hline Unknown & $46(17.2)$ \\
\hline Current smoker & $42(15.7)$ \\
\hline Chronic obstructive pulmonary disease & $30(11.2)$ \\
\hline Previous cerebrovascular accident & $23(8.6)$ \\
\hline Urea (milligrams per decilitre, IQR) & $5.4(4.5-7.0)$ \\
\hline Proton pump inhibitor & $89(33.2)$ \\
\hline Steroids & $16(6.0)$ \\
\hline Cancer operation & $83(31.0)$ \\
\hline \multicolumn{2}{|l|}{ Type of operation } \\
\hline Gastric & $28(10.4)$ \\
\hline Hepatobiliary/pancreatic & $19(7.1)$ \\
\hline Small bowel & $13(4.9)$ \\
\hline Colorectal & $76(28.4)$ \\
\hline Urological & $57(21.3)$ \\
\hline Vascular & $62(23.1)$ \\
\hline Other & $13(4.9)$ \\
\hline Perioperative antibiotics & $226(84.3)$ \\
\hline \multicolumn{2}{|l|}{ Type of intubation } \\
\hline Laryngeal mask airway & $60(22.4)$ \\
\hline Cuffed/uncuffed endotracheal tube & $207(77.2)$ \\
\hline Unknown & $1(0.4)$ \\
\hline \multicolumn{2}{|l|}{ Method of operation } \\
\hline Laparoscopic & $77(28.7)$ \\
\hline Laparoscopic-assisted & $6(2.2)$ \\
\hline Laparoscopic converted to open & $8(3.0)$ \\
\hline Open & $169(63.1)$ \\
\hline Endovascular & $8(3.0)$ \\
\hline Bowel resection & $74(27.6)$ \\
\hline Nasogastric tube & $9(3.4)$ \\
\hline Duration of surgery (minutes, IQR) & $145(87-210)$ \\
\hline Elective critical care admission & $52(19.4)$ \\
\hline \multicolumn{2}{|l|}{ Analgesia use in the first $24 \mathrm{~h}$} \\
\hline Epidural & $40(14.9)$ \\
\hline Patient controlled analgesia & $50(18.7)$ \\
\hline Wound catheter & $2(0.7)$ \\
\hline Oral analgesia only & $173(64.6)$ \\
\hline Unknown & $3(1.1)$ \\
\hline Change in analgesia strategy in the first $24 \mathrm{~h}$ & $171(63.8)$ \\
\hline Incentive spirometer & $3(1.1)$ \\
\hline
\end{tabular}


Table 2 Selected outcomes within seven and thirty days

\begin{tabular}{ll}
\hline At 7 days & \\
Severe hypoxia & $6(2.2)$ \\
Bronchospasm & $1(0.4)$ \\
Suspected pulmonary infection & $24(9.0)$ \\
Pulmonary infiltrate & $11(4.1)$ \\
Aspiration pneumonitis & $2(0.7)$ \\
Acute respiratory distress syndrome & $2(0.7)$ \\
Atelectasis & $13(4.9)$ \\
Pleural effusion & $10(3.7)$ \\
Pulmonary oedema & $6(2.2)$ \\
Any postoperative pulmonary complication & $32(11.9)$ \\
Readmission to critical care & $7(2.6)$ \\
Reintubation & $5(1.9)$ \\
Length of hospital stay (days, IQR) & $4(1-7)$ \\
At 30 days & \\
Accident and emergency attendance & $22(8.2)$ \\
Readmission & $46(17.2)$ \\
All complications & $59(22.0)$ \\
Non-pulmonary complications & $37(13.8)$ \\
Mortality & $4(1.5)$ \\
\hline
\end{tabular}

\section{Impact of PPC at day 30}

The four postoperative deaths occurred exclusively in patients who developed PPC. PPC increased the median length of hospital stay by 7 days, attendance to the emergency department by $38.8 \%$ and readmissions by $45.6 \%$ compared to if no PPC occurred (Table 5).

\section{Discussion}

This prospective multicentre cohort study investigated pulmonary complications in an unselected cohort following major elective abdominal surgery. The data set was internally and independently validated. The incidence of PPC was $11.9 \%$. PPC were associated with preoperative and intraoperative risk factors. Despite the small cohort, the development of PPC had a significant impact on length of hospital stay and 30-day outcomes. The mortalities within our cohort were exclusively in patients with a PPC. Cause of death was not examined as part of the study, and thus, we were unable to infer causality; however, length of stay and outcomes data support the morbidity secondary to PPC.

PPC have been estimated by both retrospective cohort studies and in randomised controlled trials (Seiler et al. 2009; Hemmes et al. 2014; Niggebrugge et al. 1999; Treschan et al. 2012; Holte et al. 2007; Squadrone et al. 2005; Pöpping et al. 2008). This has produced a wide disparity in the reported incidence of PPC. The definitions of PPC used in this cohort study were derived from two recent randomised controlled trials investigating differences in tidal volume settings in patients undergoing major elective abdominal surgery performed by an open procedure (Hemmes et al. 2014; Futier et al. 2013). These two studies estimated the incidence of PPC between 20 and $40 \%$. The incidence estimated in the data presented here was lower than previously described despite high internal study validity. This may be explained by differences in patients' risk factors (e.g. smoking status) and surgical procedures between the unselected cohort studied here and those randomised in previous studies (Hemmes et al. 2014; Futier et al. 2013). Another explanation may be the high numbers of laparoscopic and laparoscopic-assisted procedures performed in this series. However, these approaches are linked with longer operating times, which in this study and previous studies are associated with a higher incidence of PPC (Canet et al. 2010).

PPC was associated with worse 30-day outcomes in this study. The most striking impact of PPC was the effect on hospital length of stay. Median hospital length of stay was extended from 3 to 10 days if a PPC occurred. This is similar to data from 2001 to 2002 from the National Surgical Quality Improvement Project (NSQIP) in the USA (Dimick et al. 2004) which demonstrated that a PPC resulted in an additional six hospital days. Other infectious, cardiovascular and thromboembolic complications resulted in an additional three, two and three hospital days, respectively. In addition, PPC were associated with three times higher healthcare costs compared to other complications.

Other studies have shown continued demonstrable effects of a PPC 5 years following the index event (Khuri et al. 2005). PPCs have a multifactorial aetiology including ventilation-perfusion mismatch and hypoxemia which is a consequence of general anaesthesia, postoperative pain, diaphragmatic dysfunction, decreased chest wall compliance and depressed airway reflexes (Canet et al. 2010; Gazarian 2006; Ebell 2007). This is confounded by bacterial entry into the lower respiratory tract by aspiration of oral and pharyngeal pathogens at the time of intubation and continued leakage of secretions containing bacteria around the endotracheal tube cuff when patients are ventilated for prolonged periods (days to weeks) (du Moulin et al. 1982; Cook et al. 1998; American Thoracic Society, Infectious Diseases Society of America 2005). Colonisation of the lower respiratory tract can overwhelm the patients' mechanical, humoral, and cellular defences to establish infection following surgery (Craven and Steger 1996). Chronic airway inflammation, copious airway secretions and use of preoperative steroids causing immunosuppression may be to blame for increased PPC in patients with COPD (Banerjee et al. 2004). 
Table 3 Effect of perioperative variables on PPC

\begin{tabular}{|c|c|c|c|}
\hline & PPC No. (\%) & Yes (\%) & \\
\hline$n$ & 236 & 32 & \\
\hline Age (years, IQR) & $67(53-76)$ & $60(57-67)$ & 0.404 \\
\hline Gender & & & 0.647 \\
\hline Male & $145(61.4)$ & $21(65.6)$ & \\
\hline Female & 91 (38.6) & $11(34.4)$ & \\
\hline $\begin{array}{l}\text { Body mass index } \\
\left.\text { (kilograms/metres }{ }^{2}, \mathrm{IQR}\right)\end{array}$ & $27.3(23.8-30.5)$ & $27.1(25.6-29.9)$ & 0.742 \\
\hline $\begin{array}{l}\text { American Society of } \\
\text { Anesthesiologists physical } \\
\text { status classification system }\end{array}$ & & & 0.244 \\
\hline 1 & $50(21.2)$ & $3(9.4)$ & \\
\hline 2 & $119(50.4)$ & $13(40.6)$ & \\
\hline 3 & $58(24.7)$ & $12(37.6)$ & \\
\hline 4 & $6(2.5)$ & $2(6.2)$ & \\
\hline Unknown & $3(1.2)$ & $2(6.2)$ & \\
\hline Current smoker & $36(15.3)$ & $6(18.8)$ & 0.662 \\
\hline $\begin{array}{l}\text { Chronic obstructive } \\
\text { pulmonary disease }\end{array}$ & $22(9.3)$ & $8(25.0)$ & 0.009 \\
\hline $\begin{array}{l}\text { Previous cerebrovascular } \\
\text { accident }\end{array}$ & $21(8.9)$ & $2(6.3)$ & 0.603 \\
\hline $\begin{array}{l}\text { Urea (milligrams per decilitre, } \\
\text { IQR) }\end{array}$ & $5.6(4.5-7.3)$ & $5.4(4.0-9.4)$ & 0.886 \\
\hline Proton pump inhibitor & $80(33.9)$ & $9(28.1)$ & 0.515 \\
\hline Steroids & $13(5.5)$ & $3(9.4)$ & 0.390 \\
\hline Cancer operation & $67(28.4)$ & $15(46.9)$ & 0.035 \\
\hline Type of operation & & & 0.270 \\
\hline Gastric & $24(10.2)$ & $4(12.5)$ & \\
\hline Hepatobiliary/pancreatic & $17(7.2)$ & $2(6.3)$ & \\
\hline Small bowel & $12(5.1)$ & $1(3.1)$ & \\
\hline Colorectal & $66(28.0)$ & $10(31.3)$ & \\
\hline Urological & $55(23.3)$ & $2(6.3)$ & \\
\hline Vascular & $52(22.0)$ & $10(31.3)$ & \\
\hline Other & $10(4.2)$ & $3(9.2)$ & \\
\hline Perioperative antibiotics & $200(84.7)$ & $26(81.3)$ & 0.860 \\
\hline Type of intubation & & & 0.946 \\
\hline Laryngeal mask airway & $54(22.9)$ & $6(18.8)$ & \\
\hline $\begin{array}{l}\text { Cuffed/uncuffed } \\
\text { endotracheal tube }\end{array}$ & $181(76.7)$ & $26(81.2)$ & \\
\hline Unknown & $1(0.4)$ & $0(0.0)$ & \\
\hline Method of operation & & & 0.722 \\
\hline Laparoscopic & $72(30.5)$ & $5(15.6)$ & \\
\hline Laparoscopic-assisted & $5(2.1)$ & $1(3.1)$ & \\
\hline $\begin{array}{l}\text { Laparoscopic converted } \\
\text { to open }\end{array}$ & $6(2.5)$ & $2(6.3)$ & \\
\hline Open & $145(61.4)$ & $24(75.0)$ & \\
\hline Endovascular & $8(3.5)$ & $0(0.0)$ & \\
\hline Bowel resection & $61(25.8)$ & $13(17.6)$ & 0.079 \\
\hline
\end{tabular}

Table 3 Effect of perioperative variables on PPC (Continued)

\begin{tabular}{|c|c|c|c|}
\hline Nasogastric tube & $6(2.5)$ & $3(9.4)$ & 0.011 \\
\hline $\begin{array}{l}\text { Duration of surgery } \\
\text { (minutes, IQR) }\end{array}$ & $100(55-170)$ & $212(182-294)$ & $<0.001$ \\
\hline $\begin{array}{l}\text { Elective critical care } \\
\text { admission }\end{array}$ & $33(14.0)$ & $19(59.4)$ & $<0.001$ \\
\hline $\begin{array}{l}\text { Analgesia use in the first } \\
24 \mathrm{~h}\end{array}$ & & & $<0.001$ \\
\hline Epidural & $26(11.0)$ & $14(43.8)$ & \\
\hline $\begin{array}{l}\text { Patient controlled } \\
\text { analgesia }\end{array}$ & $40(16.9)$ & $10(31.3)$ & \\
\hline Wound catheter & $2(0.1)$ & $0(0.0)$ & \\
\hline Oral analgesia only & $166(70.3)$ & $7(21.8)$ & \\
\hline Unknown & $2(0.1)$ & $1(3.1)$ & \\
\hline $\begin{array}{l}\text { Change in analgesia strategy } \\
\text { in the first } 24 \mathrm{~h}\end{array}$ & $148(62.7)$ & $23(71.9)$ & 0.014 \\
\hline Incentive spirometer & $1(0.4)$ & $2(6.3)$ & $<0.001$ \\
\hline
\end{tabular}

A patient safety summit statement recently recommended that PPC should be a measure of healthcare quality as it is likely to require a multifaceted and multidisciplinary approach to reduce the incidence (Shander et al. 2011). The definitions used here were monitored successfully by junior surgeons with high internal study validity using prospective cross-sectional methodology described previously (Vohra et al. 2015). These data fields could be used to provide ongoing monitoring of PPC incidence. High incidences of PPC, following patient stratification and risk adjustment, may be used to indicate deficiencies in the perioperative care of patients undergoing major surgery.

Table 4 Selected factors and adjusted odds ratios for postoperative pulmonary complications

\begin{tabular}{lll}
\hline & OR $(95 \% \mathrm{Cl})$ & $p$ value \\
\hline Chronic obstructive pulmonary disease & $16.77(2.56-109.88)$ & 0.003 \\
Cancer operation & $5.13(0.41-62.5)$ & 0.205 \\
Nasogastric tube & $2.15(0.33-4.01)$ & 0.411 \\
Duration of surgery & $1.01(1.00-1.02)$ & 0.007 \\
Elective critical care admission & $4.45(0.45-43.75)$ & 0.200 \\
Analgesia use in the first 24 h & & \\
$\quad$ Epidural & Reference & 0.898 \\
$\quad$ Patient controlled analgesia & $0.83(0.05-15.26)$ & 0.279 \\
$\quad$ Wound catheter & $3.05(0.40-22.98)$ & 0.636 \\
$\quad$ Oral analgesia only & $2.56(0.23-10.54)$ & 0.247 \\
Change in analgesia strategy in & $0.24(0.02-2.70)$ & 0.782 \\
the first 24 h & & \\
Incentive spirometer & $2.93(0.12-23.83)$ & \\
\hline
\end{tabular}


Table 5 Outcomes and postoperative pulmonary complications (PPC)

\begin{tabular}{llll}
\hline & PPC & & \\
& No (\%) & Yes (\%) & \\
\hline Length of hospital stay (days, IQR) & $3(1-6)$ & $10(7-16)$ & $<0.001$ \\
At 30 days & & & \\
Accident and Emergency attendance & $26(11.0)$ & $6(27.3)$ & 0.014 \\
Readmission & $22(9.3)$ & $10(21.7)$ & 0.014 \\
Mortality & $0(0.0)$ & $4(12.5)$ & $<0.001$ \\
\hline
\end{tabular}

\section{Conclusions}

This study highlights the frequency at which PPC occur and their subsequent effects on short-term outcomes. Other studies have shown further implications for longterm patient morbidity.

The development of any PPC is associated with significant morbidity reflected in worse 7 - and 30-day outcomes as demonstrated here. Standardised care bundles and other novel strategies need to be considered to reduce PPC across all surgical patients.

\section{Additional file}

Additional file 1: Supplementary tables. (DOCX $23 \mathrm{~kb}$ )

\section{Abbreviations}

COPD: chronic obstructive pulmonary disease; PPC: postoperative pulmonary complications.

\section{Acknowledgements}

West Midlands Research Collaborative. The study was self-funded by members of the West Midlands Research Collaborative. No external funding was sought.

\section{Authors' contributions}

RV was responsible for the study design. FH, AA, GB, KE, CH, MJ, FL, JM, PN, $P R, C R$ and $S S$ collected the data. RV was responsible for the input of the data and its analysis. KP, FH, AA, GB, KE, CH, MJ, FL, JM, PN, PR, CR, SS and RV contributed to the compilation of the manuscript. KP and RV were responsible for the review and refinement of the final manuscript. All authors have read and approved the final manuscript.

\section{Competing interests}

The authors declare that they have no competing interests.

Received: 22 January 2016 Accepted: 9 May 2016

Published online: 23 May 2016

\section{References}

American Thoracic Society, Infectious Diseases Society of America. Guidelines for the management of adults with hospital-acquired, ventilator-associated, and healthcare-associated pneumonia. Am J Respir Crit Care Med. 2005;171(4): 388-416.

Arozullah AM, Daley J, Henderson WG, Khuri SF. Multifactorial risk index for predicting postoperative respiratory failure in men after major noncardiac surgery. The National Veterans Administration Surgical Quality Improvement Program. Ann Surg. 2000;232:242-53.

Banerjee D, Khair OA, Honeybourne D. Impact of sputum bacteria on airway inflammation and health status in clinical stable COPD. Eur Respir J. 2004;23: 685-91.

Bhangu A, Kolias AG, Pinkney T, Hall NJ, Fitzgerald JE. Surgical research collaboratives in the UK. Lancet. 2013;382(9898):1091-2.
Canet J, Gallart L, Gomar C, Paluzie G, Vallès J, Castillo J. Prediction of postoperative pulmonary complications in a population-based surgical cohort. Anesthesiology. 2010;113:1338-50.

Cook D, De Jonghe B, Brochard L, Brun-Buisson C. Influence of airway management on ventilator-associated pneumonia: evidence from randomized trials. JAMA. 1998;279:781-7.

Craven DE, Steger KA. Nosocomial pneumonia in mechanically ventilated adult patients: epidemiology and prevention in 1996. Semin Respir Infect. 1996;11: 32-53.

Dimick JB, Chen SL, Taheri PA, Henderson WG, Khuri SF, Campbell Jr DA. Hospital costs associated with surgical complications: a report from the private-sector National Surgical Quality Improvement Program. J Am Coll Surg. 2004a;199:531-7.

du Moulin GC, Paterson DG, Hedley-Whyte J, Lisbon A. Aspiration of gastric bacteria in antacid-treated patients: a frequent cause of postoperative colonisation of the airway. Lancet. 1982;1:242-5.

Ebell $\mathrm{MH}$. Predicting postoperative pulmonary complications. Am Fam Physician. 2007;75:1837-8.

Futier E, Constantin JM, Paugam-Burtz C, Pascal J, Eurin M, et al. A trial of intraoperative low-tidal-volume ventilation in abdominal surgery. N Engl J Med. 2013a;369(5):428-37.

Gazarian PK. Identifying risk factors for postoperative pulmonary complications. AORN J. 2006;84:616-25. quiz 627-630.

Hemmes SN, Gama de Abreu M, Pelosi P, Schultz MJ, PROVE Network Investigators for the Clinical Trial Network of the European Society of Anaesthesiology. High versus low positive end-expiratory pressure during general anaesthesia for open abdominal surgery (PROVHILO trial): a multicentre randomised controlled trial. Lancet. 2014;384(9942):495-503.

Holte K, Foss NB, Andersen J, Valentiner L, Lund C, Bie P, et al. Liberal or restrictive fluid administration in fast-track colonic surgery: a randomized, double-blind study. Br J Anaesth. 2007;99(4):500-8.

Kazaure HS, Roman SA, Sosa JA. Association of postdischarge complications with reoperation and mortality in general surgery. Arch Surg. 2012;147:1000-7.

Kehlet H, Wilmore DW. Evidence-based surgical care and the evolution of fasttrack surgery. Ann Surg. 2008;248(2):89-98.

Khuri SF, Henderson WG, DePalma RG, Mosca C, Healey NA, Kumbhani DJ, et al. Determinants of long-term survival after major surgery and the adverse effect of postoperative complications. Ann Surg. 2005;242(3):326-41 [discussion 341-343].

NICE. Surgical site infection. NICE quality standard 49. 2013. Available online at http://www.nice.org.uk/guidance/qs49/resources/guidance-surgical-siteinfection-pdf. Accessed 12 jan 2015.

NICE. Venous thromboembolism prevention quality standard. NICE quality standard 3. 2010. Available online at http://www.nice.org.uk/guidance/qs3/resources/ guidance-venous-thromboembolism-prevention-quality-standard-pdf. Accessed 12 jan 2015.

Niggebrugge AH, Trimbos JB, Hermans J, Steup WH, Van De Velde CJ. Influence of abdominal-wound closure technique on complications after surgery: a randomised study. Lancet. 1999;353(9164):1563-7.

Pöpping DM, Elia N, Marret E, Remy C, Tramèr MR. Protective effects of epidural analgesia on pulmonary complications after abdominal and thoracic surgery: a meta-analysis. Arch Surg. 2008;143(10):990-9.

Seiler CM, Deckert A, Diener MK, Knaebel HP, Weigand MA, Victor N, et al. Midline versus transverse incision in major abdominal surgery: a randomized, double-blind equivalence trial (POVATI: ISRCTN60734227). Ann Surg. 2009; 249(6):913-20.

Shander A, Fleisher LA, Barie PS, Bigatello LM, Sladen RN, Watson CB. Clinical and economic burden of postoperative pulmonary complications: patient safety summit on definition, risk reducing interventions, and preventive strategies. Crit Care Med. 2011;39:2163-72.

Squadrone V, Coha M, Cerutti E, Schellino MM, Biolino P, Occella P, et al. Continuous positive airway pressure for treatment of postoperative hypoxemia: a randomized controlled trial. JAMA. 2005;293(5):589-95.

The PROVE Network Investigators. High versus low positive end-expiratory pressure during general anaesthesia for open abdominal surgery (PROVHILO trial): a multicentre randomised controlled trial. Lancet. 2014;384(9942):495-503.

Thompson DA, Makary MA, Dorman T, Pronovost PJ. Clinical and economic outcomes of hospital acquired pneumonia in intra-abdominal surgery patients. Ann Surg. 2006;243(4):547-52.

Treschan TA, Kaisers W, Schaefer MS, Bastin B, Schmalz U, Wania V, et al. Ventilation with low tidal volumes during upper abdominal surgery does not improve postoperative lung function. Br J Anaesth. 2012a;109(2):263-71. 
Vohra RS, Spreadborough P, Johnstone M, Marriott P, Bhangu A, Alderson D, et al. West Midlands Research Collaborative. Protocol for a multicentre, prospective, population-based cohort study of variation in practice of cholecystectomy and surgical outcomes (The CholeS study). BMJ Open. 2015;5:1.

Von Elm E, Altman DG, Egger M, Pocock SJ, Gøtzsche PC, Vandenbroucke JP. Strengthening the reporting of observational studies in epidemiology (STROBE) statement: guidelines for reporting observational studies. BMJ. 2007:335(7624):806-8.

Weiser TG, Regenbogen SE, Thompson KD, Haynes AB, Lipsitz SR, Berry WR, et al. An estimation of the global volume of surgery: a modelling strategy based on available data. Lancet. 2008:372(9633):139-44.

Submit your next manuscript to BioMed Central and we will help you at every step:

- We accept pre-submission inquiries

- Our selector tool helps you to find the most relevant journal

- We provide round the clock customer support

- Convenient online submission

- Thorough peer review

- Inclusion in PubMed and all major indexing services

- Maximum visibility for your research

Submit your manuscript at www.biomedcentral.com/submit 